\title{
AKTOR LOKAL SEBAGAI AGEN OF CHANGE PEMBERDAYAAN PETANI TRANSMIGRAN (Studi Pada Komunitas Petani Transmigran di UPT. Arongo, Kabupaten Konawe Selatan)
}

Aryuni Salpiana Jabar, Iwan P., Nur Israfian Sofyan, Danial, Yoenita Djayadisastra, Waode Lusianai dan Amin Tunda

Jurusan Ilmu Kesejahteraan Sosial, Fakultas Ilmu Sosial dan Ilmu Politik, Universitas Halu Oleo, Kendari

e-mail: aryunijabar@gmail.com

\begin{abstract}
ABSTRAK
Penelitian ini bertujuan untuk mengidentifikasi upaya aktor penggerak pada komuitas petani transmigran UPT. Arongo dalam memberdayakan komunitasnya. Pelaksanaan penelitian dilakukan dengan menggunakan metode kualitatif dengan pendekatan studi kasus. Data dan informasi yang dibutuhkan dikumpulkan melalui tiga teknik pengumpulan data yaitu observasi, wawancara mendalam serta rekaman arsip. Observasi dilalukan untuk Mengidentifikasi siapa saja para tokoh lokal (local hero) yang terlibat berperan dalam pemberdayaan masyarakat setempat, wawancara mendalam dilakukan untuk mengidentifikasi upaya-upaya yang dilakukan para tokoh lokal/aktor penggerak untuk memberdayakan anggota komunitanya. Dan Rekaman arsip, dilakukan untuk menelusuri data-data yang telah tersedia seputar pelaksanaan program transmigrasi serta informasi dan berita yang memuat kehidupan masyarakat UPT. Arongo, misalnya peta lokasi pelaksanaan program, peserta/anggota program, gerakan dan kegiatan yang dilakukan warga setempat, dan seluruh telaah arsip tersebut bertujuan untuk memahami setiap proses yang berjalan pada lokasi penelitian. Hasil penelitian menunjukkan dapat diidentifikasi beberapa tokoh masyarakat setempat yang tampil sebagai figur-figur pemberi inisiatif dan pembawa perubahan di tengah masyarakat. dari berbagai aspek seperti aspek agama, pendidikan keluarga dan anak, pengetahuan seputar pertanian, kebudayaan dan kesenian serta pemberdayaan pada aspek kelembagaan, kelompok petani dan gerakan petani. Upaya aktor penggerak pada komunitas petani transmigran UPT. Arongo dalam memberdayakan komunitasnya telah menyasar dalam berbagai dimensi pemberdayaan yaitu dimensi proses pembangunan yang bermula dari pertumbuhan individual yang kemudian berkembang menjadi sebuah perubahan sosial yang lebih besar, telah membangun psikologis masyarakat petani yaitu rasa percaya diri, dan mampu mengendalikan diri dan orang lain, serta melibatkan upaya-upaya kolektif dari petani tersebut untuk memperoleh hak-hak yang seharusnya mereka dapatkan.
\end{abstract}

Kata Kunci: Aktor lokal dan Pemberdayaan Petani

\section{PENDAHULUAN}

Program transmigrasi di Indonesia telah dijalankan sejak lama bahkan sebelum Indonesia merdeka. Tercatat program transmigrasi telah dilakukan 


\section{WELVAART}

\section{JURNAL ILMU KESEJAHTERAAN SOSIAL}

bahkan sejak jaman kolonisasi sebagai bentuk politik balas budi oleh Van Deventer dengan memindahkan penduduk dari pulau Jawa yang dirasa melarat akibat kerja paksa dan culture stelsel ke bebrapa wilayah di Indonesia (Kementrian Desa, 2015). Seiring berkembangnya masa, kini pelaksanaan program transmigrasi bukan saja diarahkan pada pemerataan jumlah penduduk, tetapi juga sebagai upaya untuk mengembangkan wilayah, meningkatkan kesejahteraan transmigran dan masyarakat sekitarnya, meningkatkan pemerataan pembangunan daerah serta memperkukuh persatuan dan kesatuan bangsa.

Meskipun telah lama dijalankan, nyatanya daerah-daerah transmigrasi yang ada di Indonesia menggambarkan berbagai pola kehidupan petani transmigran. Ada yang hidup sesuai dengan harapan pelaksanaan program transmigrasi tetapi adapuladaerah-daerah transmigrasi yang berkembang jauh dari harapan pelaksanaan terlaksananya program transmigrasi. Kasus transmigrasi di wilayah Papua dan Papua Barat menggambarkan hal demikian. Dari hasil penelitiannya, Yuminarti menjelaskan bahwa meskipun berada pada provinsi yang sama, tiga lokasi unit pemukiman transmigrasi memberikan pola gambaran kehidupan para transmigran yang berbeda. Tiga UPT. Yang dimaksuda masingmasing UPT. Sobey di Kabupaten Teluk Wondama, UPT. Warikon di Kabupaten Manokwari dan UPT. Tomage di kabupaten Fakfak. Luas lahan yang diterima masing-masing kepala keluarga juga berbeda antara UPT. yang satu dengan UPT. lainnya. Pada UPT. Sobey, luas lahan yang diterima transmigran sebesar satu hektar per kepala keluarga. Hal ini Berbeda dengan kondisi UPT. Warikon dimana kepala keluarga meneruma luasan tanah yang berbeda-bedaatau tidak seragam. Hal ini disebabkan oleh lahan yang dicadangkan untuk lokasi transmigrasi ternyata merupakan lahan untuk peruntukan lainnya. Selain itu lahan yang ditempati masih status pemilikan adat. Pada UPT Tomage setiap kepala keluarga menerima lahan seluas 2 hektar namun belum bersertifikat karena masih banyak warga transmigran yang belum menetap. Hal inilah yang kemudian mempengaruhi kehidupan para transmigran di tiga lokasi tersebut (Yuminarti, 2017). 


\section{WELVAART}

\section{JURNAL ILMU KESEJAHTERAAN SOSIAL}

Di wilayah Sulawesi Tenggara sendiri pun memberikan gambaran serupa. Ada daerah-daerah transmigrasi yang maju dan bahkan mandiri, namun sebaliknya ada pula daerah transmigrasi yang jauh dari harapan. Desa Margacinta yang terletak di wilayah Kecamatan Moramo Kabupaten Konawe Selatan menjadi gambaran ideal pelaksanaan transmigrasi di wilayah Sulawesi Tenggara. Desa Margacinta telah beberapa kali mendapatkan penghargaan tingkat nasional sebagai salah satu daerah transmigrasi yang berhasil. Sebaliknya, UPT. Arongo dan Tolihe yang juga berada di daerah Kabupaten Konawe Selatan menjadi gambarana bagaimana buruknya implementasi program transmigrasi. Salah penempatan lahan dan lahan yang kurang dari pembagian yang seharusnya menjadikan akar masalah dan tidak berkembangnya pemukiman transmigrasi di wilayah tersebut. Meski demikian, kehidupan para transmigran harus tetap berlanjut sebab program telah berjalan dan para transmigran tidak memiliki pilihan lain.

Dari berbagai bentuk dan gambaran kehidupan petani transmigran, program pemberdayaan petani merupakan salah satu faktor yang mempengaruhi perkembangan kehidupan petani transmigran. Prihatin menjabarkan bahwa untuk memacu percepatan menjadi desa definitif, perlu dilakukan pembangunan dengan melibatkan/memberdayakan masyarakat agar mereka ikut berperan dalam pembangunan desa. Terkait pemberdayaan masyarakat transmigran, kaderasasi penting dilakukan untuk menyiapkan agen-agen fasilitator yang berasal dari transmigran itu sendiri agar pada gilirannya mereka mampu menggantikan peran lembaga pemerintah (Prihatin, 2007).

Kaderisasi tokoh penggerak di wilayah desa khususnya desa transmigrasi penting untuk dilakukan sebab muncul dan berperannya para tokoh lokal tersebut menjadi penyemangat dan spirit bagi pengembangan di wilayah pedesaan khususnya pada unit pemukiman transmigrasi yang ada di berbagai daerah. Selain sebagai penyemangat pembangunan, tokoh lokal juga diharapkan dapat menumbuhkan partisipasi aktif masyarakat lainnya dalam mengembangkan kehidupan di lingkungannya. Dengan partisipasi aktif segenap warga masyarakat, 


\section{WELVAART}

\section{JURNAL ILMU KESEJAHTERAAN SOSIAL}

maka pembangunan akan diarahkan sesuai dengan kapasitas dan potensi serta harapan yang diinginkan oleh masyarakat setempat.

Pemberdayaan erat kaitannya dengan partisipasi, potensi dan peningkatan kapasitas, oleh karena itu pemberdayaan tidak dapat dilepaskan dari peran institusi lokal atau aktor lokal yang ada dalam masyarakat karena elemen-elemen sosial tersebut berfungsi sebagai penggerak dalam pemberdayaan. Hasil penelitian Rahman menunjukkan bahwa keberhasilan budidaya ikan koi di desa Banyugligur dalam program pemberdayaan, merupakan keberhasilan dari penerapan penerapan yang berbasis asset lokal yaitu adanya peran aktor lokal dalam membangun kesadaran partisipasi pemuda dan mengidentifikasi potensi desa secara kolaboratif, serta adanya faktor kerjasama yang baik antara wakil pihak swasta dan pihak karang taruna (Rahman, 2018). Hal ini menunjukkan aktor lokal memiliki peranan sentral dalam pengembangan dan pemberdayaan masyarakat di pedesaan. Hal inilah yang kemudian menarik untuk peneliti kaji pada penelitian ini, yaitu mencoba menguak bagaimana upaya aktor penggerak pada komunitas petani transmigran di UPT.Arongo memberdayakan komunitasnya.

\section{METODE PENELITIAN}

Penelitian ini menggunakan metode kualitatif dengan pendekatan studi kasus untuk memahami suatu realitas yang akan diamati. Penelitian kualitatif digunakan untuk menggambarkan bagaiman tokoh lokal serta berbagai upaya yang dilakukannya untuk memebrdayakan komunitas transmigran di UPT. Arongo. Penelitian ini dilaksanakan di UPT. Arongo, Kabupaten Konawe Selatan Provinsi Sulawesi Tenggara. Informan penelitian dalam penelitian ini dipilih secara sengaja (purposive sampling) dengan pertimbangan dapat mewakili dalam menjawab rumusan permasalahan penelitian. Informan dalam penelitian ini adalah masyarakat komunitas transmigran, pemerintah desa setempat, dinas transmigrasi serta informan lainnya.

\section{PEMBAHASAN}




\section{WELVAART}

\section{JURNAL ILMU KESEJAHTERAAN SOSIAL}

Model pemberdayaan petani di tingkat komunitas berkembang spesifik menurut: a). kondisi dinamika sosial, ekonomi, budaya, politik, dan ekologi komunitas, b). perkembangan kelembagaan ketahanan pangan, c). perkembangan tahap implementasi program mapan. Kegiatan pemberdayaan seyogyanya difokuskan dan bertumpu pada pemberdayaan rumahtangga petani dengan dukungan kelembagaan ketahanan pangan yang kuat, baik itu di level komunitas, desa dan kabupaten (Sumarti, 2009).

Menurut Kieffer dalam Suharto (2010), pemberdayaan mencakup tiga dimensi yang meliputi kompetensi kerakyatan, kemampuan sosio politik, dan kompetensi partisipatif. Parson dan Suharto (2010) mengajukan tiga dimensi pemberdayaan yang merujuk pada: 1) Sebuah proses pembangunan yang bermula dari pertumbuhan individual yang kemudian berkembang menjadi sebuah perubahan sosial yang lebih besar, 2) Sebuah keadaan psikologis yang ditandai oleh rasa percaya diri, berguna dan mampu mengendalikan diri dan orang lain, 3) pembebasan yang dihasilkan dari sebuah gerakan sosial, yang dimulai dari Pendidikan dan politisasi orang-orang lemah dan kemudian melibatkan uopayaupaya kolektif dari orang-orang lemah tersebut untuk memperoleh kekuasaan dan mengubah struktur-struktur yang masih menekan.

Figur-figur lokal dalam pemberdaayan di UPT. Arongo melalukan pemberdayaan dalam beberapa implementasi dan tindakan. Masing-masing tindakan yang dilakukantanpa mereka sadari telah menyasar keberdayaan komunitas petani transmigran di UPT. Arongo.

Pada aspek keagamaan, tampil seorang ustadz Z. melalui berbagai kegiatan bimbingan keagaamaan, telah mampu membawa masyarakat UPT.Arongo baik anak-anak maupun dewasa kepada tahap perubahan keagaamaan dimana pengetahuan keagaamaan lebih baik dibandingkan sebelumnya. Pada awal kegiatan pemberdayaannya, Ustadz Z. memulai dengan cara menghidupkan kembali bangunan keagamaan berupa masjid yang ada di UPT. Arongo. Dari implementasi kegiatan pemberdayaan yang dilakukan ustadz Z. maka ustadz Z. telah mampu melakukan proses peningkatan kesadaran dan 


\section{WELVAART}

\section{JURNAL ILMU KESEJAHTERAAN SOSIAL}

keingintahuan masyarakat untuk mendalami ilmu agama, meningkatkan kemampuan anak-anak untuk mengaji, serta meningkatkan solidaritas bersama untuk memajukan aspek keagamaan di UPT. Arongo baik bangunannya maupun pengetahuan masyarakatnya.

Pada aspek Pendidikan keluarga dan Pendidikan anak. Terdapat figur Ibu MA. yang biasa dipanggil ibu S. sebagai seorang sarjana pendidikan, ibu S. mengimplementasikan ilmu dan pengetahuan yang dimilikinya dengan membagikan ilmu tersebut kepada komunitas petani di UPT. Arongo. Bersamasama dengan ibu-ibu lainnya, ibu S. giat mendorong semangat warga di UPT. Arongo untuk menyekolahkan anak-anak mereka. Akses Pendidikan warga transmigran yang terhalang oleh jarak, menjadikan ibu S. mengajak warga lainnya bersama-sama untuk mendirikan sebuah sekolah PAUD dan TK sebagai bentuk pendidikan tingkat paling dasar di wilayah transmigrasi.

Bapak S. tampil sebagai figur lokal pemberdayaan komunitas petani transmigran pada aspek budaya dan kesenian. Bapak S. merupakan suami dari Ibu S. yang merupakan tokoh penggerak pada aspek pendidikan anak dan keluarga. Bapak S. dibantu ibu S. Bersama-sama membangun kesenian tradisional Jawa asal bapak S. Ibu S. sendiri adalah transmigran asal Bali. Namun beliau bertemu dan menikah dengan bapak S. yang merupakan transmigran asal Jawa Tengah. Kesenian yang dikembangkan adalah kesenian gamelan. Kesenian ini bahkan mendapat bantuan dari pemerintah daerah berupa alat-alat musik gamelan. Masyarakat UPT. Arongo memiliki jadwal tetap untuk saling bertemu dan rembuk di satu bangunan yang terletak di samping rumah Bapak S. alat-alat gamelan pun diletakkan dan di rawat di bangunan pertemuan tersebut.

Pada aspek pemberdayaan kelembagaan komunitas petani serta gerakangerakan petani, Bapak U. tampil sebagai figur terdepan dalam mendorong masyarakat komunitas petani untuk selalu proaktif dan peka dalam meningkatkan kesejahteraan melalui peningkatan keberdayaan komunitas. Melalui berbagai pengalaman yang telah ia peroleh sebelum mengikuti program transmigrasi di UPT.Arongo, Bapak U. kemudian tampil secara vokal dalam mendampingi masyarakat komunitas petani dalam berbagai kegiatan termasuk juga kendala- 


\section{WELVAART}

\section{JURNAL ILMU KESEJAHTERAAN SOSIAL}

kendala yang dihadapi selama menjalani program transmigrasi. Wilayah UPT. Arongo berhimpitan dengan wilayah perkebunan kelapa sawit, oleh karenanya sering mengalami konflik antara pihak transmigran dengan pihak perkebunan. Bapak U. tampil dalam mendampingi warga komunitas petani untuk selalu menghadapi konflik yang mereka hadapi bersama.

Dari pendampingan dan gerakan yang dimotori oleh Bapak U. maka Bapak U. telah melakukan pemberdayaan komunitas dalam dimensi proses pembangunan yang bermula dari pertumbuhan individual yang kemudian berkembang menjadi sebuah perubahan sosial yang lebih besar pada komunitas petani transmigran di wilayah UPT. Arongo khususnya dan wilayah Konawe Selatan secara umum, telah membangun psikologis masyarakat petani yaitu rasa percaya diri, dan mampu mengendalikan diri dan orang lain, serta pembebasan yang dihasilkan dari sebuah gerakan sosial, yang dimulai dari pendidikan dan politisasi masyarakat petani transmigran di UPT. Arongo kemudian melibatkan upaya-upaya kolektif dari petani tersebut untuk memperoleh hak-hak yang seharusnya mereka dapatkan.

\section{PENUTUP}

Dari hasil penelitian di atas dapat disimpulkan: (1) diidentifikasi beberapa tokoh masyarakat setempat yang tampil sebagai figur-figur pemberi inisiatif dan pembawa perubahan di tengah masyarakat. Figur-figur tersebut semuanya berasal dari petani transmigran setempat dengan implementasi pemberdayaan dari berbagai aspek seperti aspek agama, pendidikan keluarga dan anak, pengetahuan seputar pertanian, kebudayaan dan kesenian serta pemberdayaan pada aspek kelembagaan, kelompok petani dan gerakan petani. (2) Upaya aktor penggerak pada komunitas petani transmigran UPT. Arongo dalam memberdayakan komunitasnya dengan berbagai aspek pemberdayaan dan berbagai bentuk implementasi pemberdayaan telah menyasar dalam berbagai dimensi pemberdayaan yaitu dimensi proses pembangunan yang bermula dari pertumbuhan individual yang kemudian berkembang menjadi sebuah perubahan 
sosial yang lebih besar pada komunitas petani transmigran di wilayah UPT. Arongo khususnya dan wilayah Konawe Selatan secara umum, telah membangun psikologis masyarakat petani yaitu rasa percaya diri, dan mampu mengendalikan diri dan orang lain, serta pembebasan yang dihasilkan dari sebuah gerakan sosial, yang dimulai dari pendidikan dan politisasi masyarakat petani transmigran di UPT. Arongo kemudian melibatkan upaya-upaya kolektif dari petani tersebut untuk memperoleh hak-hak yang seharusnya mereka dapatkan.

\section{DAFTAR PUSTAKA}

Aswasulasikin, A., Dwiningrum, S. I. A., \& Sumarno, S. (2015). Tuan Guru Sebagai Tokoh Pembangunan Pendidikan Di Pedesaan. Jurnal Pembangunan Pendidikan: Fondasi Dan Aplikasi, 3(1), 1-10.

Kementrian Desa, P. D. T. D. T. R. . (2015). TRANSMIGRASI Masa Doeloe, Kini dan Harapan Kedepan. Direktorat Jenderal Penyiapan Kawasan dan Pembangunan Pemukiman Transmigrasi Direktorat Bina Potensi Kawasan Transmigrasi.

Kinseng, R. A. (2017). Strukturgensi : Sebuah Teori Tindakan. Jurnal Sosiologi Pedesaan, 5(2), 127-157.

Manik, J. R. (2016). Analisis Peran Pemuda Sarjana Penggerak Pembangunan Di Pedesaan (Psp3) Terhadap Pembangunan Desa Di Kabupaten Pakpak Bharat. Jurnal Ekonomi, XXI(02), 290-308.

Nirzalin. (2013). Mendamaikan Aktor dan Struktur dalam Analisis Sosial Perspektif Teori Strukturasi Antony Giddens. Jurnal Sosiologi USK (Media Pemikiran \& Aplikasi), 3(1), 15-24.

Porawouw, R. (2016). Peran Tokoh Masyarakat Dalam Meningkatkan Partisipasi Pembangunan. Politico, 3(1), 1-17.

Prihatin, R. (2007). Pemberdayaan Masyarakat Transmigrasi Melalui Pembentukan Kader. WARTA PERENCANA, 1(7).

Rahman, N. E. (2018). Potret Pemberdayaan Masyarakat Berbasis Aset Lokal pada Kelompok Budidaya Ikan Koi di Desa Banyuglugur Kecamatan Banyuglugur Situbondo. Jurnal Penelitian Kesejahteraan Sosial, 17(3), 207216. 
Riskasari, N. (2018). Kolaborasi Aktor Pembangunan dalam Mewujudkan Desa Mandiri di DesaBongki Lengkese Kecamatan Sinjai Timur Kabupaten Sinjai Collaboration of Development Actors in Realizing Mandiri Villages in Bongki Lengkese Village, East Sinjai District , Sinjai District. Jurnal Pemikiran Dan Penelitian Administrasi Publik, 8, 121-126.

Sumarti, T. (2009). Model Pemberdayaan Masyarakat. Prosiding Seminar HasilHasil Penelitian IPB. ipb.

Tanziha, I. (2011). Model Pemberdayaan Petani Menuju Ketahanan Pangan Keluarga. Jurnal Gizi Dan Pangan, 6(1), 90.

Yuminarti, U. (2017). Kebijakan Transmigrasi dalam Kerangka Otonomi Khusus di Papua: Masalah dan Harapan ( Transmigration Policy in the Context of Special Autonomy in Papua: Problems and Expectations ). Jurnal Kependudukan Indonesia, 12(1), 13-24. 